\title{
Comparative Study Of Glucose And Xylose Production In EnZyMatic Hydrolysis By BATCH AND FED-BATCH METHOD
}

\author{
SON Yudiastuti ${ }^{1)}$, Efri Mardawati ${ }^{2)}$, MTAP Kresnowati ${ }^{3)}$, Yazid Bindar ${ }^{4)}$ \\ ${ }^{1)}$ Post Grad Student in Department of Magister Agroindustrial Technology, Faculty of Agricultural \\ Industrial Technology, Universitas Padjadjaran, Jln. Raya Bandung Sumedang Km 21, \\ Hegarmanah, Jatinagor 45363, Indonesia. \\ ${ }^{2)}$ Lecturer and Researcher in Department of Agricultural Industrial Technology, Faculty of \\ Agricultural Industrial Technology, Universitas Padjadjaran, Jln. Raya Bandung Sumedang Km \\ 21, Hegarmanah, Jatinagor 45363, Indonesia. \\ ${ }^{3)}$ Lecturer and Researcher in Department of Food Engineering, Faculty of Industrial Technology, \\ Institut Teknologi Bandung, Jln. Ganesha 10 Bandung 40132, Indonesia \\ ${ }^{4)}$ Lecturer and Researcher in Department of Chemical Engineering, Faculty of Industrial \\ Technology, Institut Teknologi Bandung, Jln. Ganesha 10 Bandung 40132, Indonesia \\ E-mail : silvia.oktavivia@gmail.com
}

\begin{abstract}
Xylose is a five-carbon chain monosaccharide that can be used as a substrate in the fermentation of low-calorie xylitol. While glucose is a six carbon chain monosaccharide that can be processed into glucose syrup as a more stable natural sweetener in the food processing industry. Xylose is xylan monomer produced from hydrolysis of hemicellulose from plants or biomass woddy biomass, while glucose is the result which is also produced in xylan hydrolysis by xylanase enzymatic hydrolysys. In the search for the source of hemicellulose, oil palm empty fruit bunch (OPEFB) as solid waste from crude palm oil processing is a source that can be utilized in this research. OPEFB waste is abundant by the increasing world demand for vegetable oil. Considering the OPEFB enzymatic hydrolysis was a heterogenous solid-liquid reaction, fed-batch feeding of the substrate was thought to improve the reaction performance. Hydrolysis experiments were performed at temperature $50^{\circ} \mathrm{C}$, pH 5 and for 96 hours hydrolysys time with substrate concentration at 15\% and enzyme dose of $1 \%$. The result showed that the feed-batch hydrolysis configuration provided a higher yield of xylose and glucose than batch configuration but insignificant.
\end{abstract}

Keywords : Enzymatic Hydrolysis, Fed-batch, glucose, Xylan, Xylanase, Xylose, Xylitol.

Diterima : 17 Maret 2018 ; Disetujui : 25 April 2018; Online Published : -

DOI : $10.24198 /$ jt.vol12n1.9

\section{INTRODUCTION}

Oil palm empty fruit bunches (OPEFB) are biomass produced from fresh fruit threshing in palm oil factory. In Indonesia, the number of this biomass is increasing as the increases of oil palm plantations area and the need for crude palm oil exports. OPEFB is often left to rot in the plantation area or used as household fuel by being burned directly though this waste can be reprocessed well into products with high economic value. The products that can be produced from this biomass conversion are the xylose and glucose. Both of these are monosaccharides, that can be obtained from OPEFB through the hydrolysis of strong acids or enzymatic hydrolysis. Hydrolysis with strong acids, will produce products with a darker color and harder to purify. In contrast, the enzymatic configuration hydrolysis process easier to purify and to control (Mardawati et al., 2014).

Xylose and glucose produced from the hydrolysis may be used simultaneously in the fermentation for xylitol production as the 
substrate and co-substrate, or used separately for the production of various product. The use of xylose as a single substrate can lead to a low yield of xylitol, since the carbon in the xylose structure consumed for cell growth (Mardawati, Trirakhmadi and Kresnowati, 2017). On the other hand, the process of xyiltol fermentation required six carbon source for growth cell. The production of glucose in xylose hydrolysis can reduce the cost of xylitol fermentation.

Batch, fed-batch and continuous are three types of operating methods in the enzymatic hydrolysis process. In the batch method, there is no addition of raw materials and no harvesting of products during the process. The substrate is inserted at the beginning of the process and the yield is harvested at the end of the process. The advantage of this method is it can be done on a small scale. The negative effect is as the substrate concentration getting bingger; the process hydrolysis will be facing in heterogenous solid-liquid reaction problem which made the solution harder to be stirred.

In the fed-batch method, the substrate or enzyme is added during the process, and the product is harvested at the end. The advantage of this method is increasing the yield product since the gradually feeding of the substrate could decrease the heterogenous solid-liquid reaction. It is the goal of this research to compare the effectiveness of batch and fedbatch methods in the enzymatic hydrolysis if OPEFB for xylose hydrolysate production to be used as the substrate for xylitol fermentation.

\section{MATERIALS AND METHOD}

\section{Oil Palm Empty Fruit Bunch (OPEFB)}

Empty fruit bunch was obtained from PTPN VIII Cikasungka Bogor, West Java, Indonesia. Before processing, the OPEFB was washed, dried and milled into rough powder then analyzed by NREL method.

\section{Xylanase}

Xylanase enzyme was purchase from Xi'an Haoxuan Bio-tech Co., Ltd, Rm. 806, Building 3, Orient Plaza, Nanerhuan East Sec., Beilin Dist., Xi'an, China. Based on DNS method analysis, the enzyme contain $340 \mathrm{U} / \mathrm{G}$ enzyme assay with $100 \%$ trough 80 mesh.

\section{Autoclave Pretreated of OPEFB}

OPEFB autoclave pretreated was held in laboratory of food microbiology department of Food Industrial Technology Universitas Padjadjaran. For each hydrolysis feed, dissolve $15 \%$ Oil palm empty fruit bunches in acetic acid buffer solution $0.05 \mathrm{M} \mathrm{pH} 5$, then proceed to pretreatment of the autoclave at $121^{\circ} \mathrm{C}$ for 15 minutes.

\section{Enzymatic Batch Hydrolysis of OPEFB}

The Enzymatic hydrolysis by batch method refers to the modified batch hydrolysis by Mardawati (2014). Hydrolysis is done in incubator shaker $250 \mathrm{~mL}$ erlenmeyer flask with $100 \mathrm{~mL}$ working volume of $50^{\circ} \mathrm{C}$ at $200 \mathrm{rpm}$ for 96 hours.

\section{Enzymatic Fed-Batch Hydrolysis of OPEFB}

This method was performed to compare the yield of xylose and glucose produced from the batch method. The fedbatch hydrolysis is done by gradually feeding the substrate four times in the first 48 hours of hydrolysis and divided into every 12 hours of hydrolysis time. Each substrate concentration is $15 \%$ and hydrolysis time for 96 hours. Xylanase dose of $1 \%$ is added just before the hydrolysis process begins. Hydrolysis is done in a $250 \mathrm{~mL}$ erlenmeyer flask in a shaker incubator at $50^{\circ} \mathrm{C}$ at $200 \mathrm{rpm}$.

\section{Analysis of Hydrolysate Content}

The hydrolysate analysis was done in department of food engineering, Bandung Institute of thechnology using HighPerformance Liquid Chromatography (HPLC) series waters 1515 with refractive index detector to determine xylose and glucose 
concentration. Colum used in this analysis was HPX87H. Details of operation method of this HPLC were: $5 \mathrm{mM} \mathrm{H}_{2} \mathrm{SO}_{4}$ as the carrier and $0.6 \mathrm{ml} / \mathrm{min}$ dilution rate. Running time of each sample was $30 \mathrm{~min}$.
Xylose and glucose in OPEFB hydrolyzate were analyzed every 24 hours to determine the increase of product yield and xylanase enzyme performance during hydrolysis process.

\section{Calculating yield of Xylose and Glucose.}

The yield of glucose and xylose were calculated using folowing equation :

$$
\begin{aligned}
& \text { Xylose Max on Hydrolisate }=\frac{M_{\text {Solid Substrate }}}{V_{\text {hydrolysis }}} \times \% \text { hemicellulose Solid Substrate } \\
& \text { Glucose Max on Hydrolisate }=\frac{M_{\text {Solid Substrate }}}{V_{\text {hydrolysis }}} \times \% \text { Cellulose Solid Substrate } \\
& \text { Xylose yield }=\frac{C_{x y l o s e}}{C_{x y l o s e} \text { max on Hydrolisate }} \times 88 \% \\
& \text { Glucose yield }=\frac{C_{\text {Glucose }}}{C_{\text {Glucose max on Hydrolisate }}} \times 90 \%
\end{aligned}
$$

\section{RESULT AND DISCUSSION}

\section{OPEFB}

The composition of lignocellulose in OPEFB, varies greatly, depending on the genetics type and environment in which the oil palm is grown (Kresnowati, Mardawati and Setiadi, 2015). Cellulose, hemicellulose, and lignin are mainly compound of lignocelulosic material. Table 1 shown the composition of OPEFB used and figured 1 shown the lignocellulosic composition that varies depending on the plant genetic and growing conditions of the environment.

Table 1. Composition of OPEFB

\begin{tabular}{cc}
\hline \hline Composition & \% dry basis \\
\hline Hemicellulose & 17,31 \\
Cellulose & 39,47 \\
Lignin & 23,25 \\
\hline
\end{tabular}

Lignin is the cellulose and hemicellulose shielding bone composed of various aromatic compounds. Glucose is monomer of cellulose, a strong hydrogen bond between glucose monomers, making cellulose very strong forming a crystalline structure.

Hemicellulose are heteropolymer composed of various five-chains monosaccharide monomers, such as xylose, arabinose, galactose and mannose, so the bonds are weaker and easier to hydrolyze. However, 80 per cent of the hemicellulose composers are xylanes which are polymers of xylose (Mardawati et al., 2014)

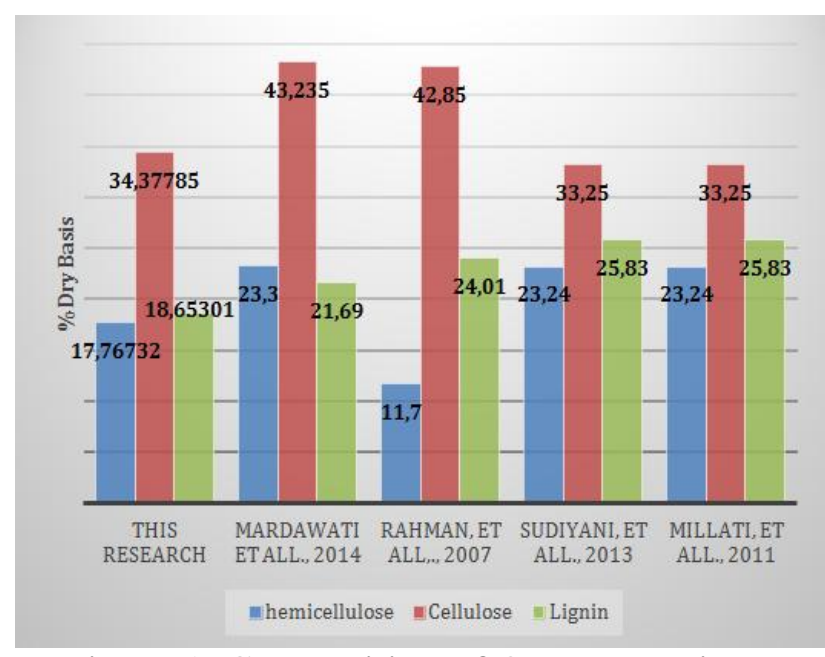

Figure 1. Composition of OPEFB Varies

Genetics and Environtment growth (\% dry basis) (Kresnowati, et all., 2015)

\section{Composition of Hydrolyzate In Batch and Fed-Batch Method}

To maintain optimum conditions of xylanase activity, acetate buffers $0.05 \mathrm{M}$ are used with $\mathrm{pH}$ 5. However, acetic acid may be an inhibitor in the hydrolysis process, so it is necessary to know the concentration during the hydrolysis process (Figure 2). 


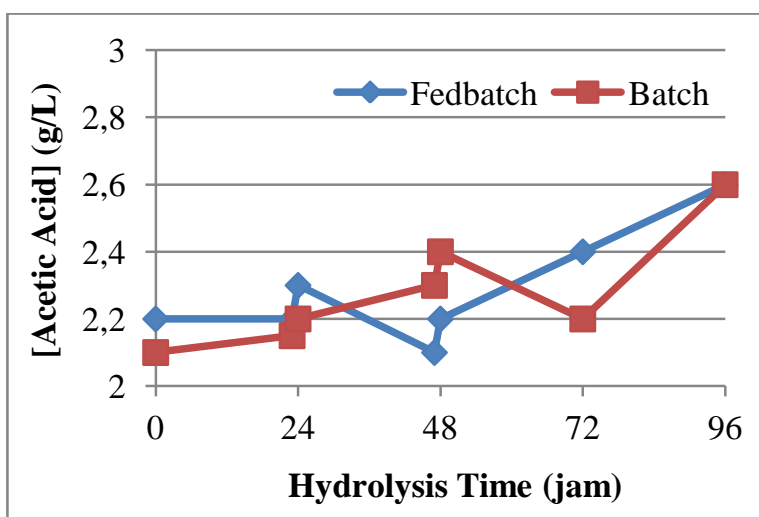

Figure 2. Acetic Acid Concentration During

Batch and Fed-batch Hydrolysis Processes

The increase of acetic acid in the hydrolyzate during hydrolysis process occurs due to the hydrolysis of acetyl groups in the heteropolymer bond of hemicellulose (Chin, et al., 2014 and Guerra-Rodriguez, et al., 2012). Further, Chin et al. (2014) explains that hemicellulosic monomers such as xylose associated with acetyl groups can be hydrolyzed to acetic acid. In the reported study there was an increase of acetic acid to a constant at a concentration of $4.7 \mathrm{~g} \mathrm{/} \mathrm{L}$ predicted when it reached a constant point, all the acetyl groups in the xylose had been converted to acetic acid. The result of this formation of acetic acid is the decrease of the yield of xylose in the hydrolysis process (Chin, et al., 2014).

The concentration of acetic acid that can be the inhibitor in the xylitol fermentation process is at a concentration of $10.5 \mathrm{~g} / \mathrm{L}$ (Ferrari, et al., 1992). In the research reported by Guerra-rodriguez, et al (2012) reported that the concentration of acetic acid in hydrolysis of $2.3-2.6 \mathrm{~g} / \mathrm{L}$ did not affect the fermentation.

\section{Concentration of Substrate in Batch and Fed-batch Configuration}

The use of different hydrolysis methods can lead to differences in xylose and glucose composition in OPEFB hydrolyzate. The main product in hydrolysis of hemicellulose by xilanse is xylose (figure 3 ).

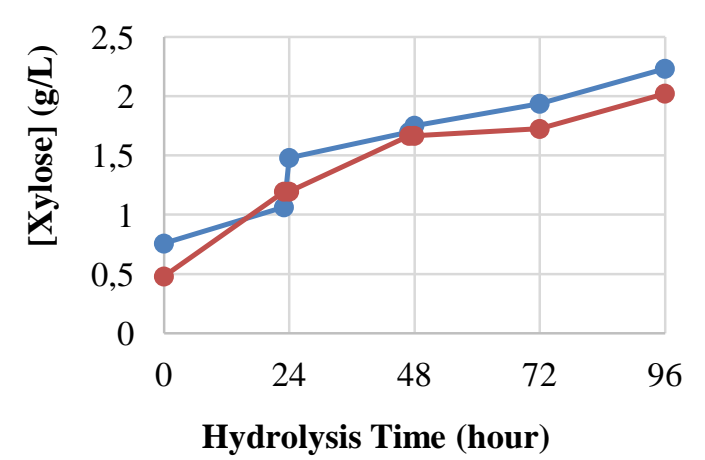

(a)

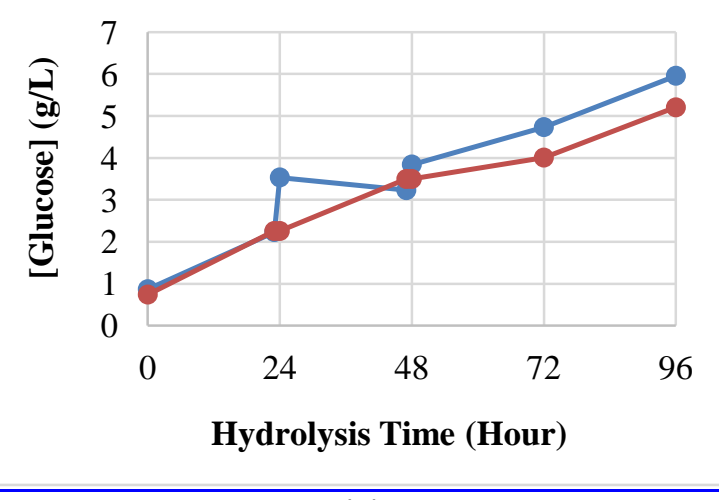

(b)

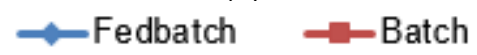

Figure 3. Concentration of Xylose (a) and Glucose (b) during Hydrolysis Process Batch and Fed-batch

From Figure 3 it can be seen that in hydrolysis fed-batch during gradual addition of substrate at 12 to 48 hours can increase the composition of glucose and xylose in hydrolyzate. Then the composition of glucose and xylose will be the same at 48 hours hydrolysis time, at that time, the volume of buffer and substrate is already in the same state in both enzymatic hydrolysis methods. The condition of the solid-liquid reaction at 48 hours is also in the same condition.

The xylose and glucose composition at 72 hours of hydrolysis is higher in the fedbatch method, because the xylanase reaction rate in the fed-batch method is greater. At the end of the hydrolysis time (96 hours) although not significantly different, the xylose composition in the hydrolysis of the fed-batch hydrolysis results is greater than that of the batch hydrolysis. Further analysis of $t$ test statistics for hydrolyzate compositions is presented in Table 2. 
Tabel 2. Composition of Xylose and Glucose in OPEFB Hydrolyzate

\begin{tabular}{ccccc}
\hline $\begin{array}{c}\text { Hydrolysis } \\
\text { Time } \\
(\text { Jam) }\end{array}$ & \multicolumn{2}{c}{ Glucose $($ g/L) } & \multicolumn{2}{c}{ Xylose (g/L) } \\
\cline { 2 - 5 } & Fed-batch & Batch & Fed-batch & Batch \\
\hline 0 & $0.9 \pm 0.07$ & $0.7 \pm 0.03$ & $0.8 \pm 0.01$ & $0.5 \pm 0.34$ \\
24 & $3.5 \pm 0.23$ & $2.3 \pm 0.22$ & $1.8 \pm 0.08$ & $1.2 \pm 0.19$ \\
48 & $3.8 \pm 0.33$ & $3.5 \pm .49$ & $1.7 \pm 0.19$ & $1.7 \pm 0.18$ \\
72 & $4.7 \pm 0.43$ & $4.0 \pm 0.37$ & $1.9 \pm 0.16$ & $1.7 \pm 0.05$ \\
96 & $5.9 \pm 0.52$ & $5.2 \pm 0.29$ & $2.2 \pm 0.17$ & $2.0 \pm 0.02$ \\
\hline
\end{tabular}

In batch hydrolysis method, substrate concentration will be higher than fed-batch method so that hydrolysis process will be limited by very heterogeneous solid-liquid reaction (Kresnowati, et al., 2015). This causes mass transfer between the enzyme and the substrate to be more difficult (Mardawati, et al., 2014).

Sun and Chen (2002) reported that substrate susceptibility to enzymes is influenced by substrate structure (degree of crystallinity), degree of polymerization, surface area and lignin content. The liquidsolid reaction is related to the surface area in the TKKS substrate which affects time transfer between enzyme and substrate. The mass transfers will increase by reducing the heterogeneous conditions of the substrate solution through the gradually addition of substrate solution.

The yield yield of xylose and glucose in fed-batch hydrolyzate was higher than the batch method hydrolyzate (Table 3). This is because the solid-liquid reaction in fed-batch hydrolysis is lighter that the xylanase enzymes could work more optimally (Sugiharto et al., 2016).

Table 3. Yield of Glucose and Xylose in Batch and Fed-batch Hydrolysate.

\begin{tabular}{ccc}
\hline \hline Products & \multicolumn{2}{c}{ Yield (\%) } \\
\cline { 2 - 3 } & Fed-batch & Batch \\
\hline Xylose & $7.6 \pm 0.6$ & $6.9 \pm 0.1$ \\
Glucose & $9.1 \pm 0.8$ & $7.9 \pm 0.5$ \\
\hline
\end{tabular}

The reduction rate of xylan or substrate concentration (Figure 4) can be illustrated by assuming the formation of xylose products in OPEFB hydrolyzate.
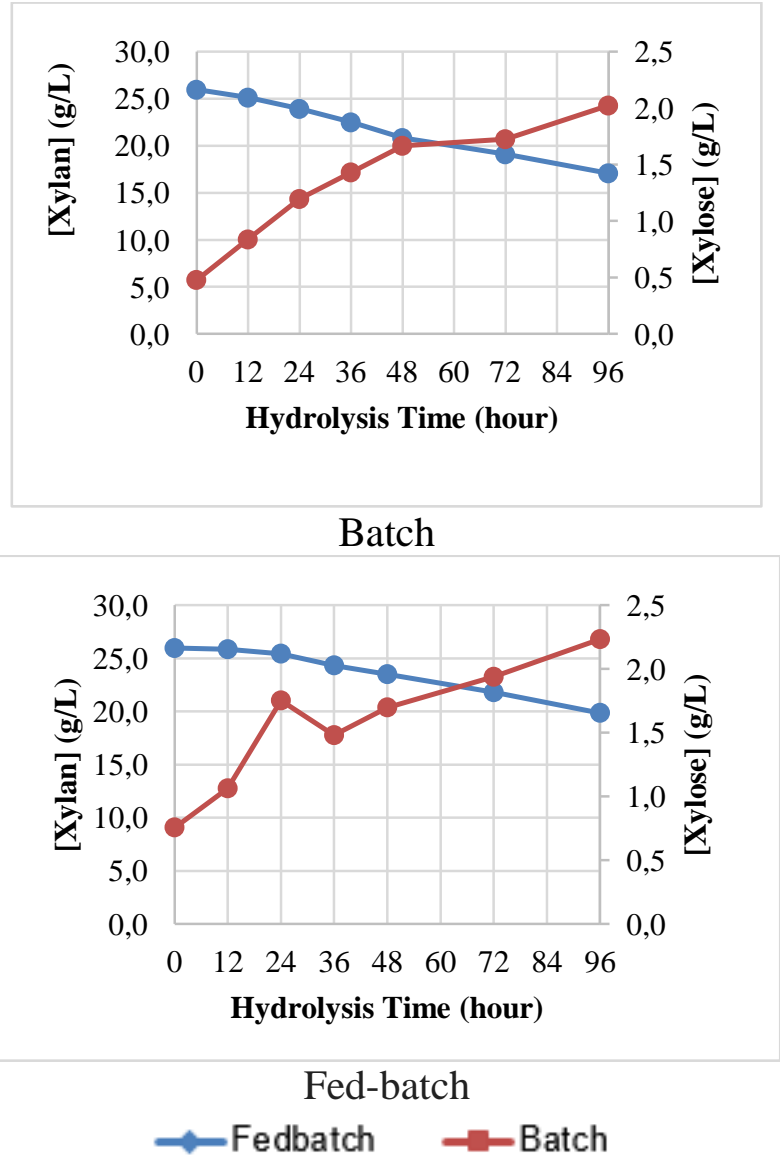

Figure 4. Substrate consumption and xylose production during hydrolysis time

Figure 4 can also be used to describe the concentration of the substrate in the hydrolysis process, represented by the substrate mass $(\mathrm{g})$ contained in the buffer solution. In batch hydrolysis, the OPEFB mass is greater than the OPEFB mass in fed-batch hydrolysis. In fedbatch hydrolysis, OPEFB can still be immersed by a buffer solution, whereas in 
batch hydrolysis, the surface height of OPEFB solids in the erlenmeyer glass is proportional to the buffer solution.

In this study the results of xylose and glucose concentrations obtained did not differ significantly between batch and fed-batch hydrolysis methods. This is due to low substrate concentrations, if the concentration of the substrate is increased by more than $15 \%$, there will be significant different product concentrations between batch and fed-batach hydrolysis methods. What happens in this experiment also occurs in experiments conducted by $\mathrm{He}$ et al (2017) and Gao, et al (2014) which states that at a substrate concentration of more than $20 \%$, xylose can be produced with a number far greater than the substrate concentration below $15 \%$.

He, et al (2017) conducted a comparison of enzymatic hardwood hydrolysis by batch method and fedbatch with $15 \%$ substrate concentration to produce bio-sugar. The report states that the amount of bio-sugar produced from fedbatch hydrolysis is 10.7 times greater than the batch hydrolysis method. Subsequently reported subsequent fed-batch

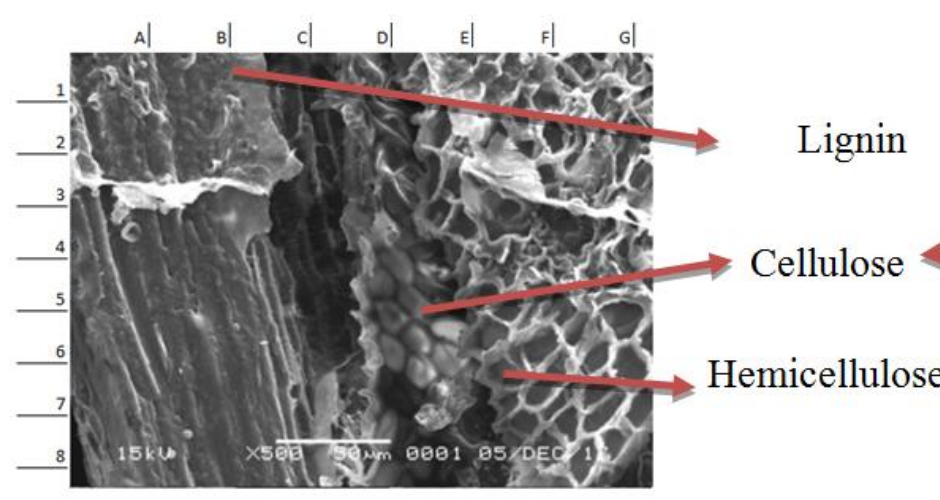

Batch enzymatic hydrolysis would be more effective at substrate concentrations starting with a substrate concentration of $15 \%$ with fedding intervals every 24 hours.

Gao et al. (2014) reported that enzymatic hydrolysis of fed-batch bagasse was conducted with a substrate concentration of $12-33 \%$ and could increase the concentration of xylose, glucose, and selobiose produced compared to the batch method. Furthermore, Gupta et al. (2012) reported that at a substrate concentration of $20 \%$, the fed-batch hydrolysis of the juliflora enzymatic propellant can produce monosaccharides up to $127 \mathrm{~g} / \mathrm{L}$ compared with a batch method which yields only monosaccharides of $80.78 \mathrm{~g} / \mathrm{L}$.

\section{Effect of Enzymatic Hydrolysis Method on the Morphological Characteristics.}

Figure 5 shows a comparison between batch and fed-batch enzymatic hydrolysis method. Figure $4 \mathrm{a}$ is the morphological crosssection structure of OPEFB hydrolysis with batch mode, white figure $5 \mathrm{~b}$ show morphological structure of OPEFB which hydrolysis with fed-batch mode.

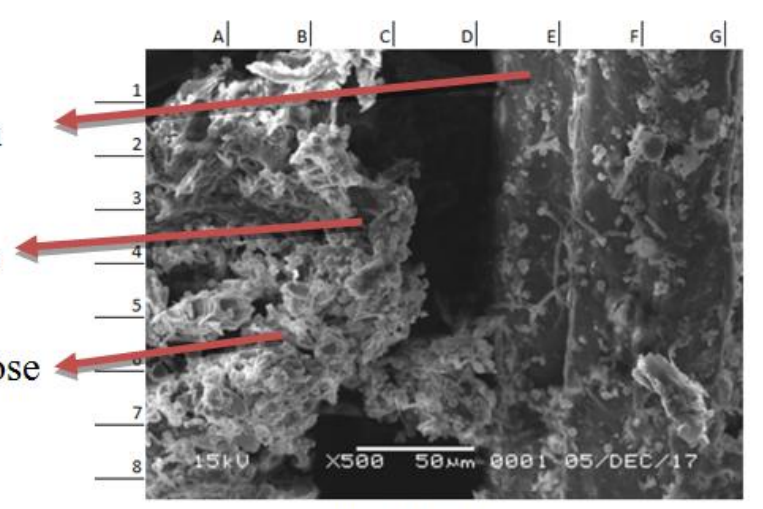

Fed-batch

Figure 4. Morphological cross-section of hydrolysis solid residu

Its sees obviously that the OPEFB morphological which had fed-batch method cause a substantial removal of lignin and some of the internal microfibers appeared in comparison with batch mode. Holistically, there is a dramatic change in the visual aspect with much crumble on its surface at fed-batch mode. Crumbel on the surface desribe as a thin layer in the middle of lignocellulose which mostly contains hemicellulose (Kristensen et al., 2016). Meanwhile the porous bubble structrure are broken cellulose layer (Mulakhudair, Hanotu and Zimmerman, 2016), its explain the larger glucose composition on hydrolyzed than xylose. It seen that the bubble porous structure is much broken than the thin layer structure. 


\section{CONCLUSIONS AND SUGGESTION}

The results showed that enzymatic hydrolysis of lignoselulosic on OPEFB with fed-batch method increase xylose and glucose yield than batch method, but insignificant in $15 \%$ of substrat concentration. The enzymatic fed-batch method can increase the performance of the process up to $28 \%-33 \%$ for xylose and glucose yield. More efforts should be spent on the optimization of higher substrate concentration to produce more xylose and glucose in fed-batch configuration. Moreover substrate particle size optimization to reduce the effect of solid-liquid reaction between OPEFB solution and xylanse.

\section{ACKNOWLEDGEMENTS}

This research was funded by Directorate of Higher Education, Indonesia Ministry of National Education (DIKTI) under the scheme of National Strategic Research “The production of 'green' Xylitol:Integrated Convertion of Biomass Waste of Palm Oil into Bioethanol and valuable Chemical".

\section{LITERATURE CITED}

Jönsson, L. J. and Martín, C. (2016) 'Pretreatment of lignocellulose: Formation of inhibitory by-products and strategies for minimizing their effects', Bioresource Technology. doi: 10.1016/j.biortech.2015.10.009.

Kresnowati, M., Mardawati, E. and Setiadi, T. (2015) 'Production of Xylitol from Oil Palm Empty Friuts Bunch: A Case Study on Bioefinery Concept', Modern Applied Science, 9(7), p. 206. doi: 10.5539/mas.v9n7p206.

Kresnowati, M. T. A. P. et al. (2016) 'Microbial Production of Xylitol from Oil Palm Empty Fruit Bunch Hydrolysate: Effects of Inoculum and $\mathrm{pH}$ ', Journal of Engineering and Technological Sciences, 48(5), pp. 523533. doi:

10.5614/j.eng.technol.sci.2016.48.5.2.

Kresnowati, M. T. A. P., Desiriani, R. and
Wenten, I. G. (2017) 'Ultrafiltration of hemicellulose hydrolysate fermentation broth', AIP Conference Proceedings, 1818. doi: 10.1063/1.4976888.

Kristensen, J. B. et al. (2016) 'Biotechnology for Biofuels Cell-wall structural changes in wheat straw pretreated for bioethanol production'. doi: 10.1186/1754-6834-15.

Mardawati, E. et al. (2014) 'The Enzymatic Hydrolysis of Oil Palm Empty Fruit Bunches to Xylose', Journal of the Japan Institute of Energy, 93, pp. 973978.

Mardawati, E. et al. (2015) 'Microbial production of xylitol from oil palm empty fruit bunches hydrolysate: The effect of glucose concentration', J. Jpn. Inst. Energy, 94, pp. 769-774. doi: 10.3775/jie.94.769.

Mardawati, E. et al. (2017) 'Evaluation of the enzymatic hydrolysis process of Oil Palm empty fruit bunch using crude fungal xylanase', ARPN Journal of Engineering and Applied Sciences, 12(18), pp. 5286-5292.

Mardawati, E., Trirakhmadi, A. and Kresnowati, M. (2017) 'Kinetic study on Fermentation of xylose for The Xylitol Production', 1(1), pp. 1-6.

Mulakhudair, A. R., Hanotu, J. and Zimmerman, W. (2016) 'Exploiting microbubble-microbe synergy for biomass processing: Application in lignocellulosic biomass pretreatment', Biomass and Bioenergy, 93, pp. 187193. doi: 10.1016/j.biombioe.2016.07.014.

Schuler, Michael L and Kargi, F. (1992) Bioprocess Engineering, Basic Concepts.

Sugiharto, Y. E. C. et al. (2016) 'Enzyme feeding strategies for better fed-batch enzymatic hydrolysis of empty fruit bunch', Bioresource Technology. Elsevier Ltd, 207, pp. 175-179. doi: 10.1016/j.biortech.2016.01.113.

Vandenbossche, V. et al. (2014) 'A new lignocellulosic biomass deconstruction 
process combining thermo-mechano chemical action and bio-catalytic enzymatic hydrolysis in a twin-screw extruder', Industrial Crops and Products. doi: 10.1016/j.indcrop.2014.02.022.

He, L., Han, Q., jameel, H., Chang, H., Philips, R., Wang, Z. 2017. Comparison of one stage batch and fed-batch enzymatic hydrolysis of pretreated hardwood for the production of biosugar. Appl Biochem Bioethanol. DOI : 10.1007/s12010-017-2633-y.

Gupta, R., Kumar, S., Gomes, J., Kuhad, R.C. 2012. Kinetic Study of Batch and fedbatch enzymatic saccharification of pretreated substrate and subsequent fermentation to ethanol. Biotechnology for Biofuels. 5:16. http://biotechnologyforniofuels.com/cont ent/5/1/16.

Guerra-Rodriguez, E., Portilla-Rivera, O M., Jarquin-Enriquez, L., Ramirez, J A., Vazquez, M. 2011. Acid Hydrolysis of
Wheat Straw : a Kinetic Study. Biomass and Bioenergy 36 (2012) 346 - 255. Doi $=10.1016 /$ j.biombioe .2011 .11 .005

Gao, Y., Xu, J., Yuan, Z., Zhang, Y., Liu, Y., Liang, C. 2014. Optimization of Fedbatch enzymatic hydrolysis from alkalipretreated sugarcane baggase for highconcentration sugar production. Bioresources Technology. DOI = http://dx.doi.org/10.1016/j.biotech.2014. 05.034 .

Ferrari MD., Neirotti E., Albornoz C., Saucedo E. 1992. Ethanol production from eucalyptus wood hemicellulose hydrolysate by Pichia stipitis. Biotechnol Bioeng, 40 : 753 - 759

Chin, S X., Chia, C H., Fang, Z., Zakaria, S., Li, X K., Zhang, F. 2014. A kinetic Study on Acid Hydrolysis of Oil Palm Empty Fruit Bunch Fibers Using a Microwave Reactor System. Energy and Fuels, $\quad 2589 \quad-\quad 2597$. dx.doi.org/10.1021/ef402468z 